Journal of Rehabilitation Research and Development Vol. 27 No. 4, 1990

Pages 397-410

\title{
Static pressure seal of earmolds
}

John Macrae, PhD

National Acoustic Laboratories, Chatswood, New South Wales 2067, Australia

\begin{abstract}
Four experiments were carried out to investigate the effect on the static pressure seal of earmolds made from currently used impression and earmold materials; the occasional practice of making more than one earmold from an impression; the earmoldmaker buildup of impressions; and the multistage buildup of impressions by the impression taker. Experiment 1 showed that the chance of sealing the ear with earmolds made by the ordinary two-stage technique with only general buildup of the impression was approximately 10 percent and that none of the impression or earmold materials significantly improved the chance of obtaining a seal. Experiment 2 showed that the chance of obtaining a seal with multiple earmolds made from the one impression was zero, or very close to zero. Experiment 3 revealed that the chance of obtaining a seal increased to 55 percent when the earmold was made from an impression which was specially built up by the earmoldmaker. Experiment 4 showed that the chance of sealing the ear with earmolds made from multistage impressions was significantly greater ( 87.5 percent) than sealing the ear with those made from impressions specially built up by the earmoldmaker.
\end{abstract}

Key words: ear impressions, earmolds, static pressure seal.

\section{INTRODUCTION}

As hearing aids have become progressively smaller and have changed from being mainly body-worn to mainly head-worn, the microphone has come closer to the point where amplified sound is emitted from the earmold. Con-

Address all correspondence and reprint requests to: John Macrae, National Acoustic Laboratories, 126 Greville St., Chatswood, New South Wales 2067, Australia. sequently, the seal provided by earmolds has become increasingly important, particularly to profoundly hearingimpaired clients who use hearing aids with very high gains. Approximately 10 percent of the clients to whom the National Acoustic Laboratories (NAL) provides aids require hearing aids with 2-cc coupler gains of $65 \mathrm{~dB}$ or greater (4). These clients require earmolds which provide a high degree of seal but many experience problems created by the leakage of sound through air pathways around the earmold. For example, in a study of the post-aural hearing aid gain requirements of adults with severe to profound hearing impairment carried out recently at NAL by Byrne, Parkinson, and Newall,* 17 out of 47 subjects ( 36 percent) initially presented with acoustic feedback sufficient to limit the amount of gain that they used to less than optimum. In some cases where very high-gain hearing aids are necessary, the leakage of sound through air pathways around the earmold is the factor that limits the amount of gain which can be provided, and therefore becomes the factor that determines whether a head-worn hearing aid can be used.

There are several pathways through which sound can radiate out of an ear blocked by an earmold. Presuming that the tubing from the hearing aid has been properly connected into the earmold and that the earmold is not vented, sound can propagate through the material of the earmold or the tubing; vibrate the earmold as a whole; radiate through the tissues, cartilage, or bone surrounding the ear canal; or pass through an air pathway between the earmold and the walls of the canal. The term acoustic leak refers

*Denis Byrne, Aaron Parkinson, and Philip Newall: In-person conversation, July $9,1989$. 
Journal of Rehabilitation Research and Development Vol. 27 No. 4 Fall 1990

to an air pathway between the earmold and the walls of the meatus through which sound can travel out of the ear canal. The elimination of this pathway is the main means available for reducing the radiation of sound out of the ear canal when using a hearing aid because the other propagation pathways are relatively inefficient and largely uncontrollable. Although hearing aid fitters can increase the wall thickness of the tubing to some extent and perhaps choose an earmold material with relatively high mass per unit area, they cannot prevent sound from radiating into or out of the ear through the tissues, cartilage, and bone surrounding the earmold.

Leakage of sound around the earmold provides unintentional, uncontrolled, and variable venting in many hearing aid fittings. The reduction of the low frequency response of hearing aids that results from a poor seal by the earmold is undesirable for many profoundly deaf clients who are only able to hear low frequency sounds (1). Acoustic leakage through air pathways around earmolds also increases the likelihood of acoustic feedback. When leakage of sound occurs around an earmold, a proportion of the output signal from the hearing aid radiates back to the hearing aid's microphone. When the proportion of the output being fed back to the microphone at a particular frequency equals the gain of the hearing aid at that frequency and is in phase with the input, audible oscillation occurs. The amplification provided by the hearing aid during oscillation exceeds considerably the amount appropriate for the user's hearing loss at the frequency at which oscillation occurs; such high output levels are not safe for the remaining hearing of the user.

Because oscillation only occurs when the gain of the hearing aid equals or exceeds the attenuation present in the feedback pathway, it can be eliminated by reducing the gain of the hearing aid. However, an unfortunate consequence of this course of action may be inadequate amplification of sound (5). Even when the transmission loss in the feedback pathway is greater than the gain of the hearing aid and there is no audible oscillation, a small proportion of the output of the aid may radiate back to the microphone and combine with the input, changing its spectrum. This change in the spectrum of the input signal produces an undesirable change in the frequency response of the aid, introducing unwanted peaks (2). It follows that the needs of the clients with profound hearing impairment are best met by an earmold that has no air pathway between the sides of the earmold and the walls of the ear canal (i.e., an earmold that seals the ear).

Many factors determine whether an earmold will provide a static pressure seal: 1) the material used in taking the impression of the ear; 2) the technique used by the impression taker: should a buildup be applied when taking the impression? and, 3) the material and techniques used by the earmoldmaker when making the earmold: should the earmoldmaker apply a buildup to the impression before making the earmold? 4) what is the relative importance of these various factors in determining whether an earmold provides a static pressure seal of the ear? To obtain answers to these questions, a series of four experiments were carried out which investigated the effect of the following on the static pressure seal of earmolds: 1) currently used impression and earmold materials; 2) multiple earmolds-the occasional practice of making more than one earmold from an impression; 3) impression modifications, such as patting down impressions and earmoldmaker buildup of impressions; and, 4) multistage buildup of impressions-the threestage impression technique developed by Fifield, Earnshaw and Smither (3).

During the course of the experiments, the relationship between the static pressure seal and dimensions of the ear canal segment of earmolds was also investigated.

\section{GENERAL METHODS}

\section{Subjects}

The composition of the subject groups was approximately 63 percent male and 37 percent female. The age of the subjects ranged from 22 to 48 years; the mean was 36 to 38 years of age. All subjects were examined by an otolaryngologist prior to inclusion in any experiment and had cerumen and debris removed from their ears. Other than sensorineural hearing losses, none of the subjects had any signs or symptoms of diseases or disorders of the ear during the course of the experiments.

\section{Static pressure seal}

In each of the experiments, earmolds were assessed to determine whether they provided a static pressure seal of the ear. The assessments were carried out with a Danplex Impedance Meter Model ZA21. The tubing embedded in the earmold was connected to the air pump and manometer of the impedance meter and the pressure of the air enclosed in the ear canal was increased to an overpressure of 200 $\mathrm{daPa}$ and, if possible, maintained at that level for 5 seconds. Subjects were encouraged to talk during this period in order to establish whether movements of the jaw broke the seal. If there was no loss of pressure during the 5 seconds, the earmold was classed as providing a static pressure seal of the ear. If there was a fall in pressure, the earmold was classed as having a leak. 


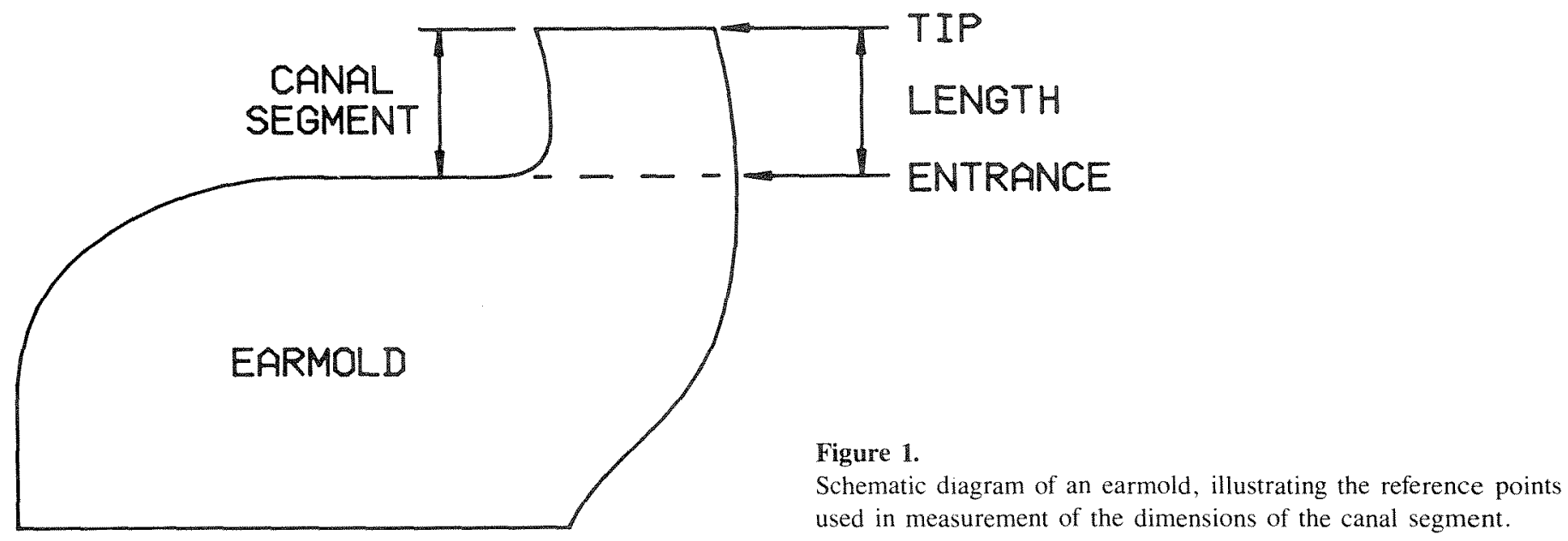

\section{Dimensions}

Dimensions of the ear canal segment of the earmolds were measured with a Sylvac digital caliper. All the dimension measurements on the earmolds were carried out under binocular $2 \mathrm{x}$ magnification. The purposes of the magnification were to: 1) enable the experimenter to ensure that the jaws of the caliper did not leave any visible compression of the earmolds made from soft materials; and, 2) enable the experimenter to clearly perceive individual landmarks on the earmolds which were used to determine the points at which measurements were to be carried out.

Figure 1 illustrates the reference points used in the measurements. The length of the part of the earmold corresponding to the outer half of the ear canal was measured with one jaw of the caliper set at the end of the canal segment (referred to as the tip), and the other jaw set at the beginning of the ear canal segment (referred to as the entrance). Because the ear canal part of the earmold was oval in cross-section in all subjects (Figure 2), both the major axis (the long axis) and the minor axis (the short axis) were measured at the canal entrance and at the canal tip. Measurements were made of the length of the canal segment (LTH), the long axis at the canal entrance (ELA), the short axis at the canal entrance (ESA), the long axis at the canal tip (TLA), and the short axis at the canal tip (TSA). The canal tip provided a natural reference point for measurements but it was more difficult to carry out the measurements at exactly the same point on each occasion at the canal entrance. However, it was found that with growing familiarity with the earmolds of a particular subject, individual landmarks could be used to ensure reasonable consistency of the point of measurement within each subject. Each measurement on every earmold was repeated three times and the mean of the three values was taken as the estimate of the true value.

\section{Statistical analyses}

Throughout the investigations, $\mathrm{X}^{2}$ tests were used to evaluate the statistical significance of the differences between the proportions of earmolds which provided a static pressure seal and the proportions of earmolds which had a static pressure leak. The statistical significance of the differences between the mean dimensions of earmolds which provided a seal and earmolds which had a leak was evaluated by using $t$-tests for independent means. The significance of the difference between the mean dimensions of different types of earmolds were evaluated in the fourth

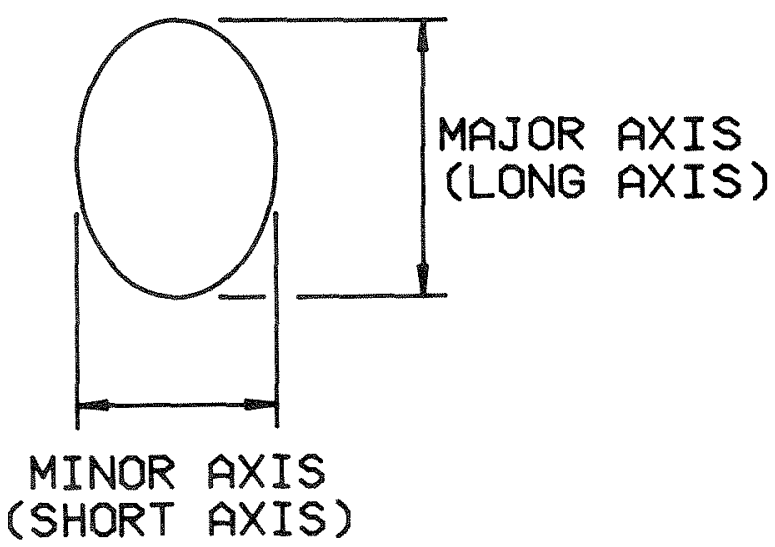

Figure 2.

Schematic diagram of a cross-section of the canal segment of a typical earmold, illustrating the major (long) and minor (short) axes. 
Journal of Rehabilitation Research and Development Vol. 27 No. 4 Fall 1990

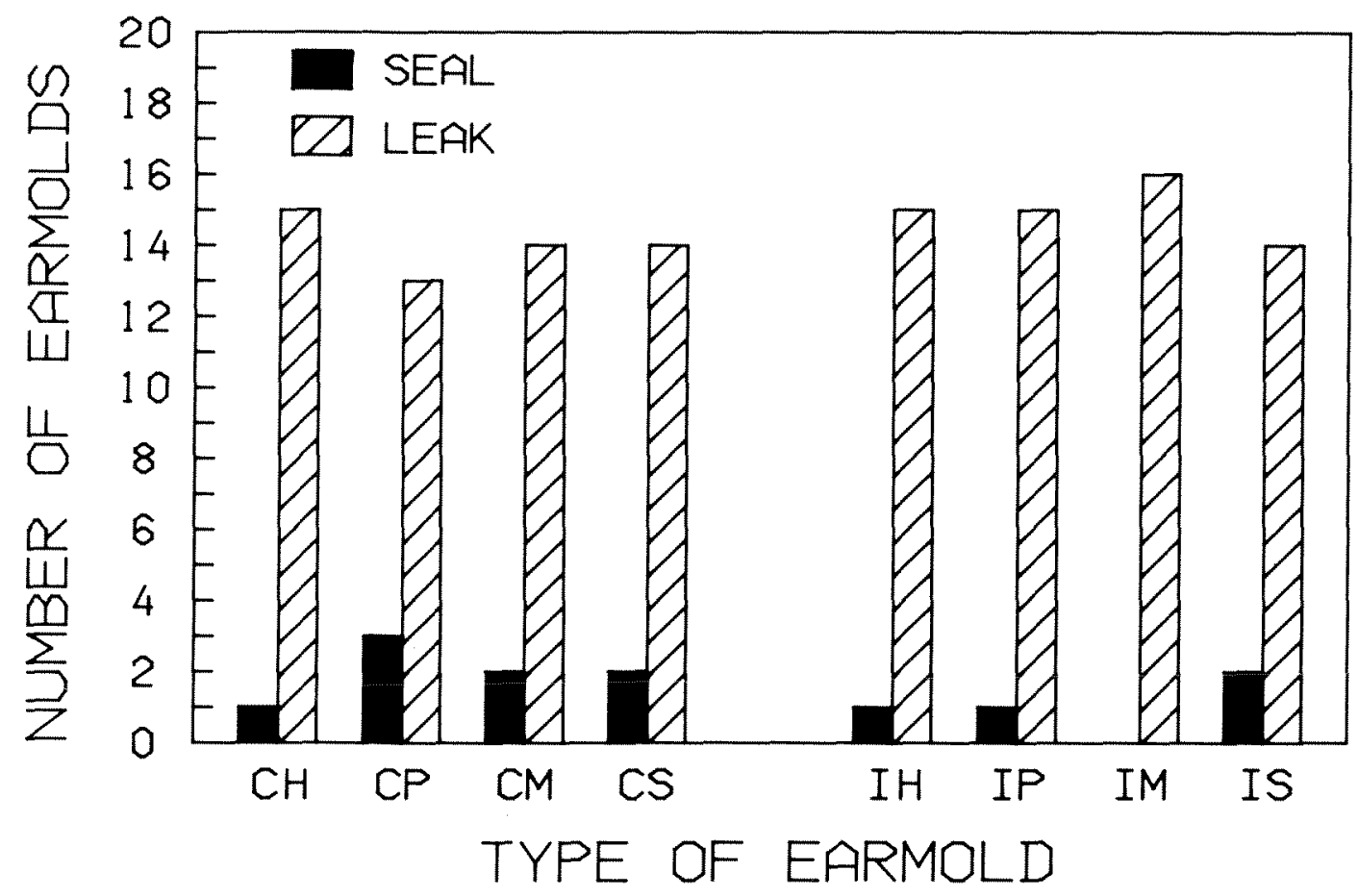

Figure 3.

Number of earmolds in each category which provided a static pressure seal and the number of earmolds which had a static pressure leak.

experiment by repeated measures of analysis of variance, followed by planned comparisons when the outcome proved significant.

The relationships between the earmold dimensions and the static pressure seal were investigated by using the discriminant analysis technique. The discriminant function for predicting static pressure seal as the dependent variable from earmold dimensions as the independent variables was calculated by means of a stepwise approach, using the minimization of Wilks' lambda as the controlling criterion. The independent variables were examined at each step for entry into or removal from the discriminant function. The criterion for entry into the function was set at a probability of 0.05 and the criterion for removal was set at a probability of 0.10 . The level of significance was set at $p<0.05$ for all statistical analyses.

\section{EXPERIMENT 1: IMPRESSION AND EARMOLD MATERIALS}

The influence of two different impression materials and four different earmold materials on the static pressure seal were investigated. At the time of the experiment, two main classes of material were used to take ear impressions at NAL: materials based on dimethyl siloxane which set by a condensation cross-linking reaction and contain an inert oil in the base paste $\left({ }^{\circledR}\right.$ Copolsil, ${ }^{\circledR O}$ Otikon Putty), and dental materials based on polyvinyl siloxane which set by an addition cross-linking reaction ( ${ }^{\circledR}$ Reprosil) or based on polyether rubber ( ${ }^{\circledR}$ Impregum F). ${ }^{\circledR}$ Copolsil was chosen to represent the first group of materials and Impregum to represent the second group. ${ }^{\circledR}$ Copolsil was used throughout NAL for the general run of impressions. ${ }^{\circledR}$ Impregum was used to take single stage impressions when a considerable delay was likely to occur before the impression was invested in the matrix material in which the earmold would be cast.

Four main types of earmold material were in use at the time of the experiment: 1) methyl methacrylate, commonly known as hard acrylic; 2) polyvinyl chloride plus 52 percent $w / w$ of a phthalic acid-based polyester liquid plasticizer marketed under the trade name ${ }^{\circledR}$ Polyplus; 3 ) ethylene-propylene copolymer marketed under the trade name ${ }^{\circledR}$ Microlite; and, 4) silicone rubber of the polydimethylsiloxane type, commonly known as silicone rubber. All four materials were used in the experiment. 


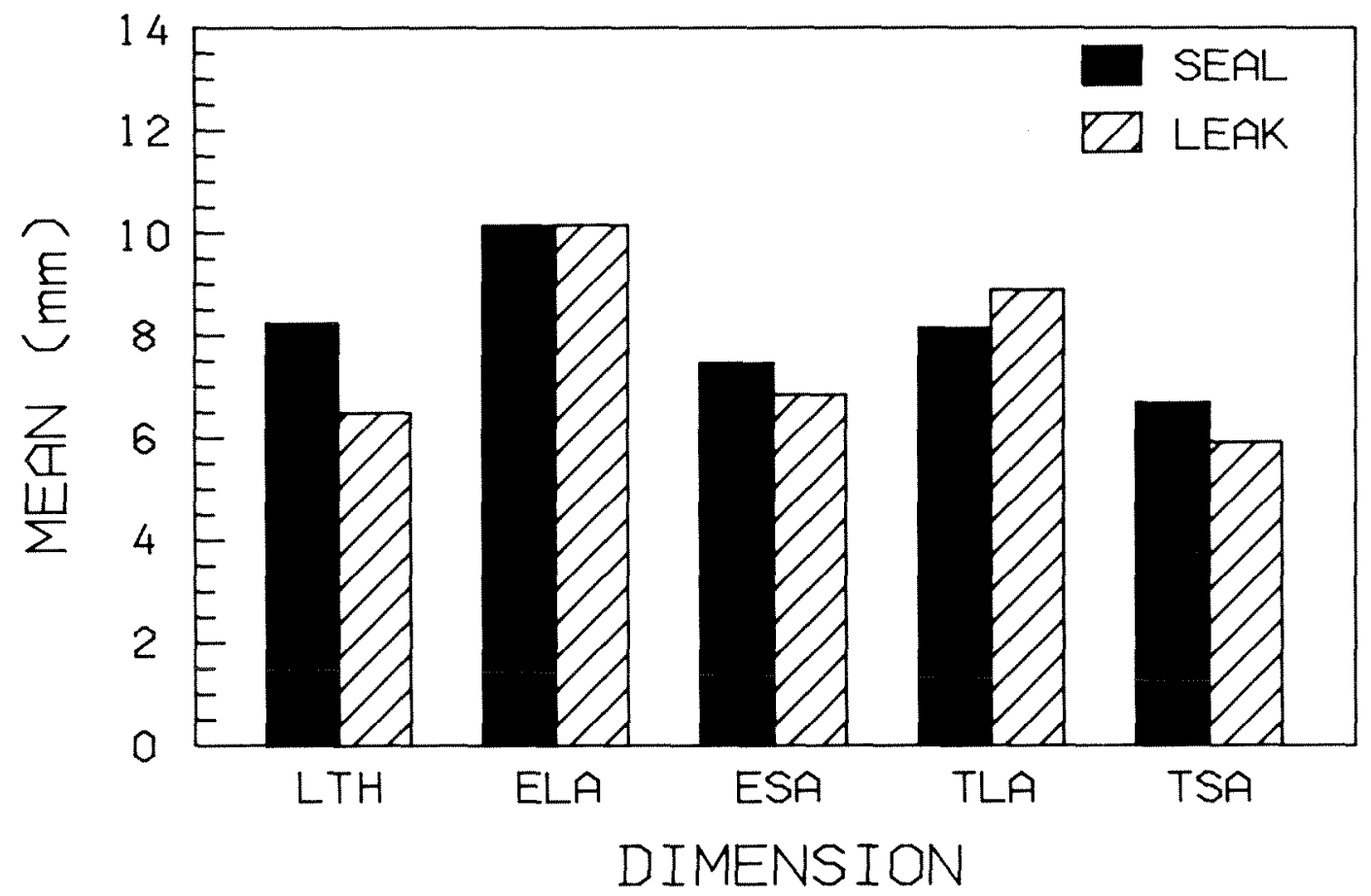

Figure 4.

Means of the various dimensions for the 12 earmolds which provided a static pressure seal and the 116 earmolds which had a static pressure leak.

\section{Method}

Subjects. Sixteen subjects were used in this experiment: 6 female and 10 male. Their ages ranged from 22 to 48 years, with a mean age of 36 years.

Procedure. Four ${ }^{\circledR}$ Copolsil (C) impressions and four ${ }^{\circledR}$ Impregum (I) impressions of the same ear of each of the 16 subjects were obtained. The four ${ }^{\circledR} \mathrm{Copolsil}$ impressions and the four ${ }^{\circledR}$ Impregum impressions were used to make four earmolds, each of a different kind of material: hard acrylic (H); ${ }^{\circledR}$ Polyplus (P); ${ }^{\circledR}$ Microlite (M); and, silicone rubber $(\mathrm{S})$. Therefore, eight earmolds were made for each subject, four from ${ }^{\circledR}$ Copolsil impressions and four from Impregum impressions. The four impressions of each type of material were assigned at random to the four types of earmold. The impressions were dipped in wax to give them a general buildup before the earmolds were made.

\section{Results}

Static pressure seal. Twelve of the 128 earmolds provided a static pressure seal. Figure 3 shows the number of earmolds in each category which sealed the canal and the number which had a leak. The results of $X^{2}$ tests showed that the differences between the proportions of earmolds in each category that provided a static pressure seal were not significant. Eight of the 64 earmolds made from ${ }^{\circledR}$ Copolsil impressions and four of the 64 earmolds made from ${ }^{\circledR}$ Impregum impressions provided a seal. The results of a $\mathrm{X}^{2}$ test indicated that this difference was not significant $\left(\mathrm{X}^{2}=1.47, \mathrm{p}=0.23\right)$. The differences between the proportions of the earmolds made from the various earmold materials that provided a seal were also not significant.

Dimensions. Figure 4 illustrates the means of the various dimensions for the 12 earmolds that provided a static pressure seal and the 116 earmolds that had a leak. The results of $t$-tests showed the significance of the differences between the mean dimensions of the earmolds that provided a seal and those of the earmolds that had a leak are given in Table 1. The mean LTH, ESA, and TSA dimensions of the earmolds that provided a seal were significantly larger than those of the earmolds that had a leak.

The relationship between earmold dimensions and the static pressure seal was investigated using the discriminant analysis technique. The discriminant function for predicting static pressure seal as the dependent variable from earmold dimensions as the independent variables was calculated by means of a stepwise approach. The results of the analysis are given in Table 2. The LTH dimension was the only dimension which entered the discriminant function. The 
Journal of Rehabilitation Research and Development Vol. 27 No. 4 Fall 1990

Table 1.

Results of $t$-tests of the differences between the mean dimensions of 12 earmolds which provided a static pressure seal and 116 earmolds which had a static pressure leak $(\mathrm{df}=126)$.

\begin{tabular}{cccccc} 
& & \multicolumn{4}{c}{ DIMENSION (mm) } \\
& LTH & ELA & ESA & TLA & TSA \\
\hline$t$ & 2.95 & .035 & 2.07 & 1.62 & 2.42 \\
$\mathbf{p}$ & .004 & .972 & .041 & .107 & .017 \\
\hline
\end{tabular}

$\mathrm{LTH}=$ length of canal segment $; \mathrm{ELA}=$ entrance long axis; $\mathrm{ESA}=$ entrance short axis; $\mathrm{TLA}=$ tip long axis; $\mathrm{TSA}=\mathrm{tip}$ short axis; $\mathrm{df}=$ degrees of freedom; $\mathrm{p}=$ probability

Table 2.

Results of discriminant analysis for predicting static pressure seal from earmold dimensions, using a stepwise approach to the entry of the independent variables.

\begin{tabular}{cccccccc}
\hline $\begin{array}{c}\text { VARIABLES } \\
\text { ENTERED }\end{array}$ & $\begin{array}{c}\text { EIGEN } \\
\text { VALUE }\end{array}$ & $\begin{array}{c}\text { CANON. } \\
\text { CORREL. }\end{array}$ & $\begin{array}{c}\text { WILKS } \\
\text { LAMBDA }\end{array}$ & $\mathbf{X}^{\mathbf{2}}$ & df & $\mathbf{p}$ \\
\hline LTH & .069 & .254 & .935 & 8.386 & 1 & .004
\end{tabular}

$\mathrm{df}=$ degrees of freedom; $\mathrm{p}=$ probability $; \mathrm{LTH}=$ length of canal segment.

standardized canonical discriminant function coefficient for the LTH variable had a magnitude of 1.00 and was positive in sign.

\section{Discussion}

Because only 12 of the 128 earmolds provided a static pressure seal, the chance of sealing the ear with earmolds made by the usual two-stage technique with only general buildup of the impression was rather low (approximately 10 percent) and the chance of obtaining a static pressure seal was not improved by the use of either of the impression materials or any of the earmold materials.

With the exception of the ELA and TLA dimensions, the earmolds which provided a seal had larger dimensions. The most important was the LTH dimension, which was the only dimension to enter the discriminant function. This may have been due to the relatively small number of earmolds which provided a seal. The standardized canonical discriminant function coefficient for this dimension was positive in sign, which implies that the greater the length of the canal segment, the more likely it is that an earmold made by the ordinary two-stage technique will provide a static pressure seal.

\section{EXPERIMENT 2: MULTIPLE EARMOLDS}

Occasionally, it is convenient to request that the earmoldmaker manufacture more than one earmold from a single impression. This circumstance might arise when earmolds made from different materials or earmolds made in different styles are to be provided to the hearing aid user and only a limited amount of time is available for taking impressions. The aim of Experiment 2 was to investigate the effect on the static pressure seal of earmolds of making more than one earmold from the one impression.

\section{Method}

Subjects. The same 16 subjects were used in this experiment as were used to investigate the effects of impression and earmold materials.

Procedure. For each subject, one impression was taken of the same ear used in Experiment 1, using ${ }^{\circledR}$ Otikon Putty impression material. ${ }^{\circledR}$ Otikon Putty is similar to ${ }^{\circledR} \mathrm{Copolsil}$, but with less oil in the base paste, and is equivalent to ${ }^{\circledR}$ Copolsil as an impression material. Four earmolds were made from each impression: a hard acrylic $(\mathrm{H})$; a ${ }^{\circledR}$ Polyplus $(\mathrm{P})$; a ${ }^{\oplus}$ Microlite $(\mathrm{M})$; and a silicone rubber (S). Each impression was fully dipped in molten wax to provide it with a general buildup, and a silicone rubber master earmold was then made from the impression by the usual method. This earmold was used like an impression to make the four earmolds and was discarded when all four had been made. The master earmold was not dipped in wax, specially built up or modified in any other way during the manufacture of the four earmolds.

\section{Results}

Static pressure seal. None of the 64 earmolds provided a static pressure seal. An $X^{2}$ test was carried out to determine the significance of the difference between the proportion of earmolds that provided a static pressure seal in Experiment 2 ( 0 out of 64$)$ and the proportion of earmolds that provided a static pressure seal in Experiment 1 (12 out of 128). The difference was significant $\left(X^{2}=\right.$ $6.40, \mathrm{p}=0.011)$.

Dimensions. The dimensions of the multiple earmolds of Experiment 2 were compared with those of the single earmolds made from single impressions from Experiment 1. Figure 5 shows the mean dimensions of the 64 earmolds of Experiment 2 compared with the mean dimensions of the 128 earmolds of Experiment 1 . The results of the $t$-tests showed the significance of the differences between the mean dimensions of the earmolds of the two experiments (Table 3). The multiple earmolds of Experiment 2 were signifi- 


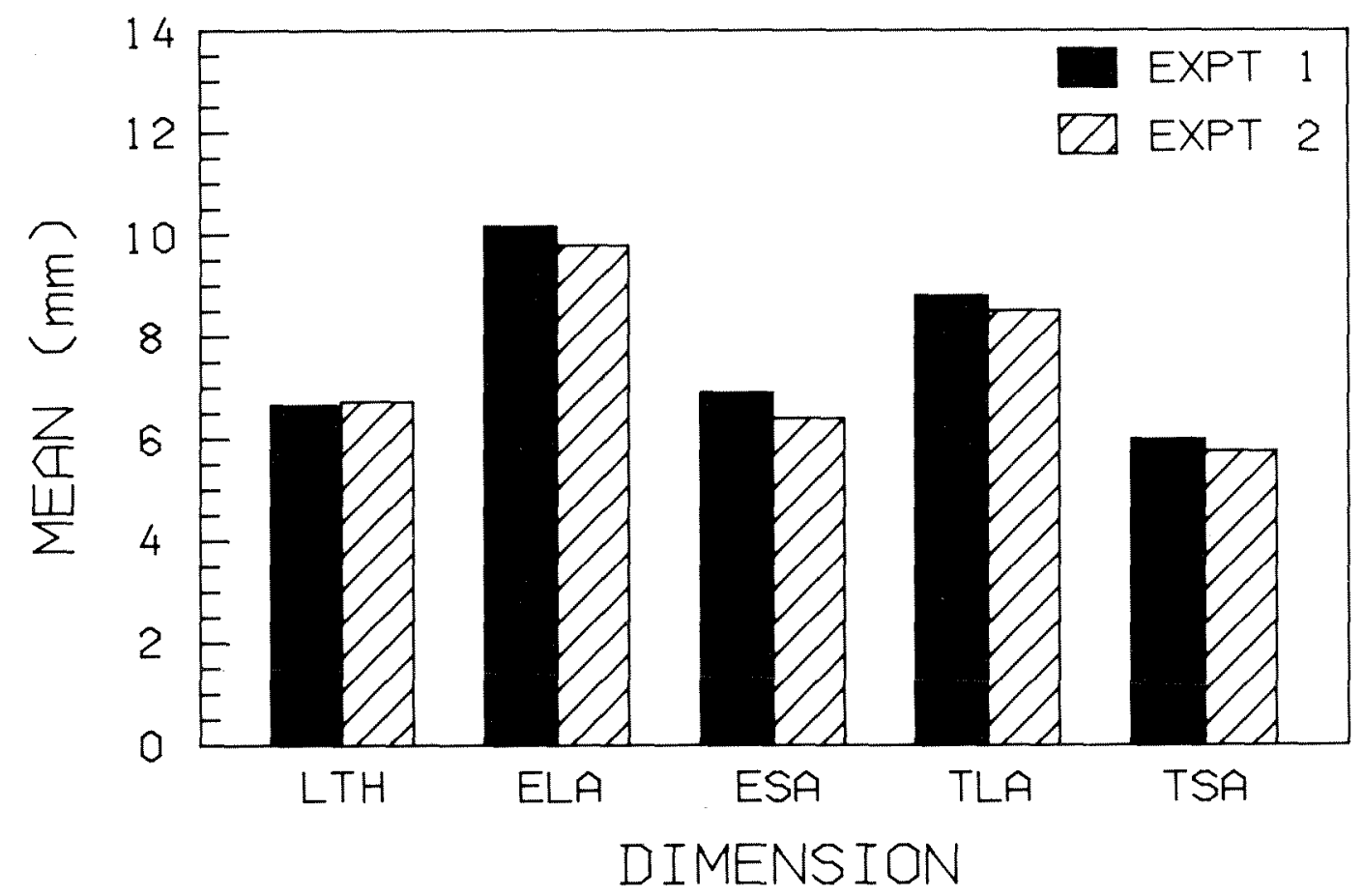

Figure 5.

Mean dimensions of the 64 earmolds of Experiment 2 compared with the mean dimensions of the 128 earmolds of Experiment 1.

cantly smaller in the ESA dimension than the single earmolds of Experiment 1.

\section{Discussion}

Making several earmolds from a single impression reduced the chance of sealing the ear canal to zero or very close to zero. This occurred presumably because the procedure of making more than one earmold from a single impression resulted in earmolds that were inferior in the ESA dimension to single earmolds made from single impressions.

\section{EXPERIMENT 3: IMPRESSION MODIFICATIONS}

The effectiveness of two types of modification of impressions for improving the static pressure seal provided by earmolds was examined. The first type of modification (performed by the impression taker) consisted of patting down the surface of the impression material after it had been syringed into the ear but before it had set. The patting down consisted of the application of gentle pressure to and the smoothing down of the outer surface of the impression material. The second type of modification (performed by the earmoldmaker) consisted of applying wax buildup to the impression with a hot wax knife before the impression was invested in the matrix material from which the earmold was cast. Various degrees of buildup were applied by the earmoldmaker, depending on the amount of hearing aid gain to be provided to the user, with greater amounts of buildup being applied the greater the average hearing loss of the user.

Except for multistage impressions, a small amount of buildup was applied by the earmoldmaker to all impres-

Table 3.

Results of $t$-tests of the differences between the mean dimensions of the earmolds of Experiment 1 and the earmolds of Experiment 2.

\begin{tabular}{lccccc}
\hline & \multicolumn{4}{c}{ DIMENSION (mm) } \\
& LTH & ELA & ESA & TLA & TSA \\
\hline$t$ & 0.29 & 1.83 & 3.31 & 1.31 & 1.51 \\
$\mathbf{p}$ & .771 & .068 & .001 & .193 & .134
\end{tabular}

LTH = length of canal segment; ELA = entrance long axis; $E S A=$ entrance short axis; $\mathrm{TLA}=$ tip long axis; $\mathrm{TSA}=$ tip short axis; $\mathrm{p}=$ probability. 
Journal of Rehabilitation Research and Development Vol. 27 No. 4 Fall 1990

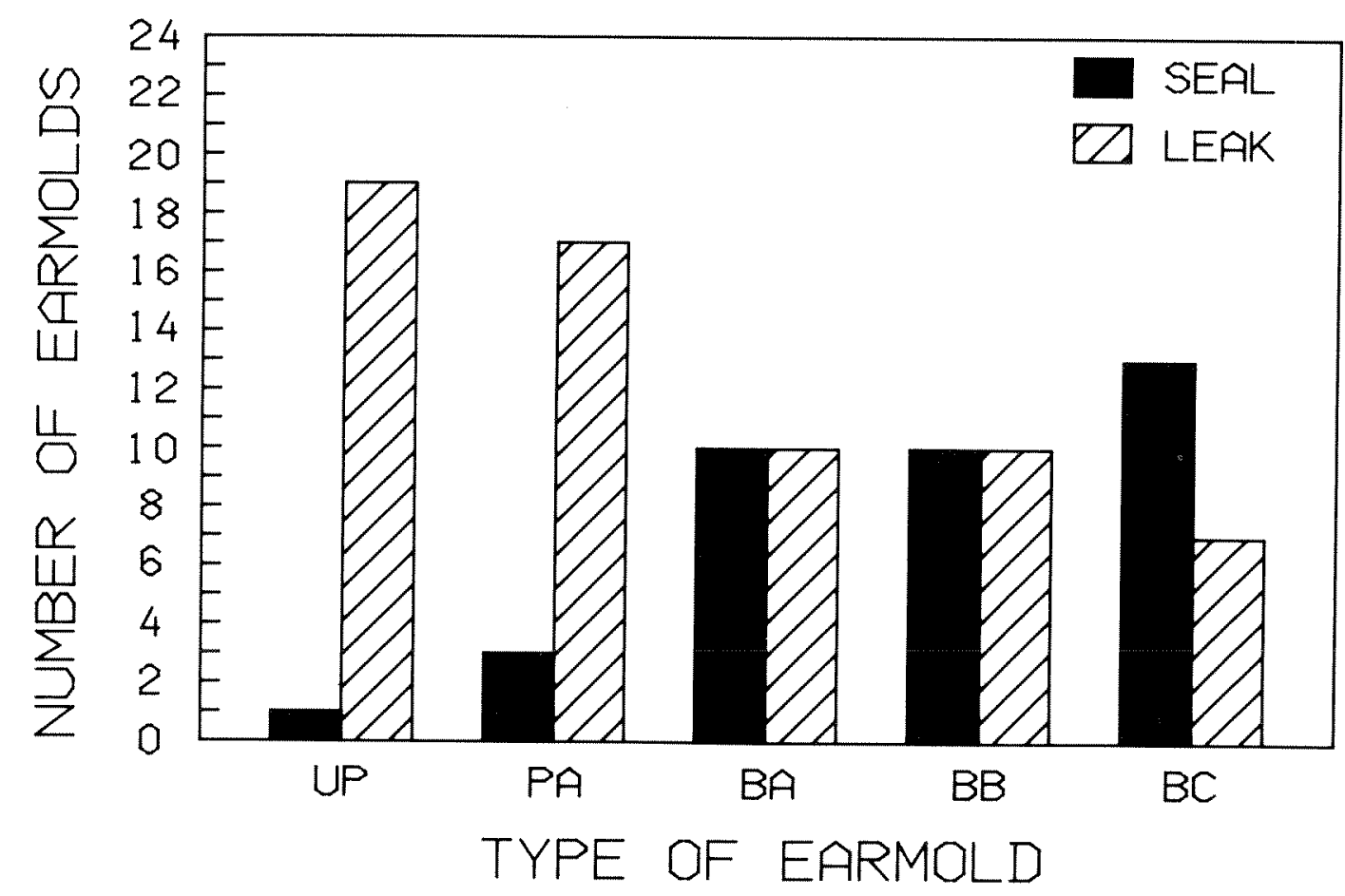

Figure 6.

Number of earmolds in each category which provided a static pressure seal and the number which had a static pressure leak.

sions by dipping the impression in molten wax, whether or not special buildup had been applied. The two forms of buildup are referred to as general buildup and special buildup. Special buildup impressions were given a general buildup after the special buildup had been applied.

\section{Method}

Subjects. Twenty subjects, 13 males and seven females participated in this Experiment. Their ages ranged from 22 to 48 years, with a mean age of 36 years. Fourteen of these subjects had participated in Experiments 1 and 2.

Procedure. Five impressions were taken of one ear of each subject in one sitting, using ${ }^{\circledR}$ Otikon Putty impression material. One impression was unpatted (UP) and the other four were patted. Five silicone rubber earmolds were made, one from each impression. Each of the four patted impressions were assigned at random to one of the four remaining experimental conditions with the intention of canceling out any effects in the average results that might arise from the order in which the impressions were taken. No special buildup was applied to one of the impressions before the associated earmold was made and the earmold made from this impression was referred to as the PA earmold (made from a patted impression).
Buildup considered by the earmoldmaker to be appropriate for the amount of gain provided for an average hearing threshold level of $80 \mathrm{~dB}$ was applied to another of the patted impressions before the earmold was made; the earmold made from this impression was referred to as the BA earmold (made from an impression with Buildup A). Buildup considered by the earmoldmaker to be appropriate for the amount of gain provided for an average hearing threshold level of $100 \mathrm{~dB}$ was applied to the fourth impression; the earmold made from this impression was referred to as the BB earmold (made from an impression with Buildup B). Buildup considered by the earmoldmaker to be appropriate for an average hearing threshold level of $120 \mathrm{~dB}$ was applied to the fifth impression; the earmold made from this impression was referred to as the $\mathrm{BC}$ earmold (made from an impression with Buildup C).

\section{Results}

Static pressure seal. Figure 6 shows the number of earmolds in each category that provided a static pressure seal and the number that had a leak. Thirty-seven earmolds provided a seal and 63 earmolds had a leak. Thirty-three of the specially built-up earmolds provided a seal and 27 had a leak. $X^{2}$ tests were used to determine the signifi- 


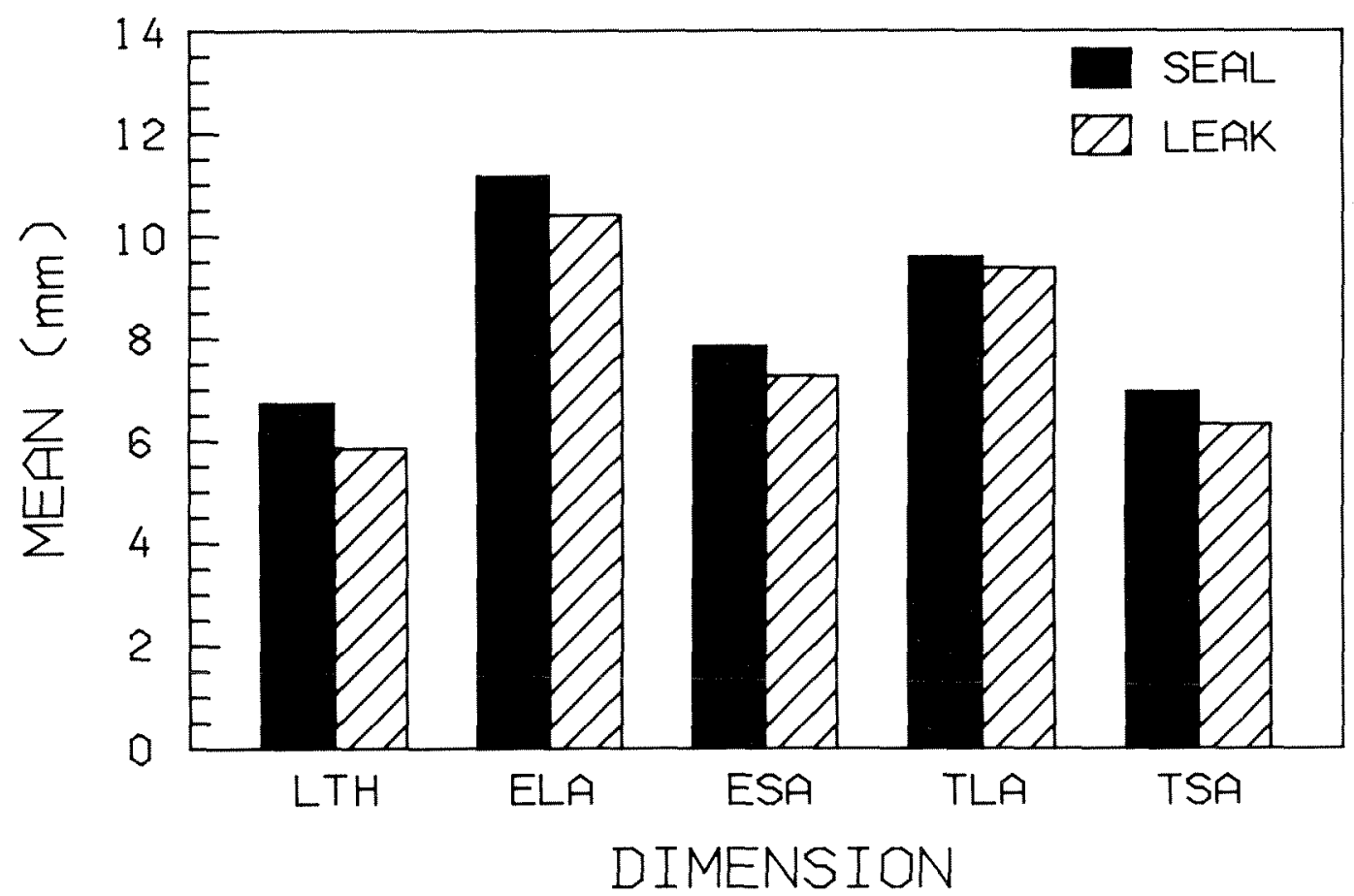

Figure 7.

Mean dimensions of the 37 earmolds which provided a static pressure seal compared with the mean dimensions of the 63 earmolds which had a static pressure leak.

cance of the differences between the proportions of earmolds that provided a static pressure seal in the various categories and the results are given in Table 4 . The proportion of PA earmolds that provided a static pressure seal was not significantly greater than the proportion of UP earmolds that provided a seal. The proportions of the three categories of specially built-up earmolds that provided a static pressure seal were all significantly greater than the proportions of both of the categories of unbuilt-up earmolds that provided a seal. The proportions of the three categories of specially built-up earmolds that provided a static pressure seal were not significantly different from each other.

Dimensions. Figure 7 presents the mean dimensions of the 37 earmolds that provided a static pressure seal compared with the mean dimensions of the 63 earmolds that had a static pressure leak. The results of $t$-tests that showed the significance of the differences between the mean dimensions of the earmolds that provided a seal and those that had a leak are given in Table 5. The mean LTH, ELA, ESA, and TSA dimensions of the earmolds that provided a static pressure seal were significantly larger than those that had a static pressure leak. The relationship between earmold dimensions and static pressure seal was investigated using the discriminant analysis technique (Table 6).
The LTH, ESA, TLA, and TSA dimensions entered the discriminant function as significant predictors of static pressure seal. Figure 8 illustrates the standardized canonical discriminant function coefficients for these dimensions.

\section{Discussion}

Patting the impression alone does not significantly increase the likelihood of obtaining a seal. Special buildup clearly increases the proportion of earmolds that provide a static pressure seal ( 55 percent of the specially built-up earmolds provided a seal) but the increasing amounts of special buildup applied in this experiment did not result in a significant increase in the proportion of earmolds that provided a seal.

Although the mean LTH, ELA, ESA, and TSA dimensions of the earmolds that provided a static pressure seal were significantly larger than those of the earmolds that had a static pressure leak, the LTH, ESA, TLA, and TSA dimensions entered the discriminant function as significant predictors of the static pressure seal. The discriminant function coefficients for the LTH, ESA, and TSA dimensions were positive in sign which implies that for these variables, the larger the dimension, the more likely it is that the earmold will provide a static pressure seal. 
Journal of Rehabilitation Research and Development Vol. 27 No. 4 Fall 1990

Table 4.

Results of $\mathrm{X}^{2}$ tests of the significance of differences between proportions of UP, PA, BA, and BC earmolds which provided a static pressure seal (results for BB earmolds are same as for BA earmolds).

\begin{tabular}{cccccc}
\hline COMPARISON & $\mathbf{X}^{2}$ & $\mathbf{p}$ & COMPARISON & $\mathbf{X}^{2}$ & $\mathbf{p}$ \\
\hline UP - PA & 1.111 & .292 & PA - BA & 5.584 & .018 \\
UP - BA & 10.157 & .001 & PA - BC & 10.417 & .001 \\
UP - BC & 15.824 & .000 & BA-BC & 0.921 & .337 \\
\hline
\end{tabular}

$\mathrm{UP}=$ unpatted; $\mathrm{P}=$ patted; $\mathrm{BA}=$ buildup $\mathrm{A} ; \mathrm{BC}=$ buildup $\mathrm{C}$.

Table 5.

Results of $t$-tests of differences between mean dimensions of 37 earmolds which provided a static pressure seal and 63 earmolds which had a static pressure leak.

\begin{tabular}{cccccc}
\hline & \multicolumn{5}{c}{ DIMENSION (mm) } \\
& LTH & ELA & ESA & TLA & TSA \\
\hline$t$ & 10.99 & 7.04 & 9.79 & 0.35 & 12.17 \\
$\mathrm{p}$ & .001 & .009 & .002 & .558 & .001 \\
\hline
\end{tabular}

$\mathrm{LTH}=$ length of canal segment; $\mathrm{ELA}=$ entrance long axis; $\mathrm{ESA}=$ entrance short axis; $T L A=$ tip long axis; $T S A=$ tip short axis.

Table 6.

Results of discriminant analysis for predicting static pressure seal from earmold dimensions, using a stepwise approach to the entry of the independent variables.

\begin{tabular}{lcccccc}
\hline $\begin{array}{l}\text { VARIABLES } \\
\text { ENTERED }\end{array}$ & $\begin{array}{c}\text { EIGEN } \\
\text { VALUE }\end{array}$ & $\begin{array}{c}\text { CANON. } \\
\text { CORREL. }\end{array}$ & $\begin{array}{c}\text { WILKS } \\
\text { LAMBDA }\end{array}$ & $\mathbf{x}^{2}$ & df & $\mathbf{p}$ \\
\hline $\begin{array}{l}\text { LTH, ESA, } \\
\text { TLA, TSA }\end{array}$ & .469 & .565 & .681 & 36.89 & 4 & .000
\end{tabular}

$\mathrm{df}=$ degrees of freedom; $p=$ probability; LTH = length of canal segment; $\mathrm{ESA}=$ entrance short axis; TLA = tip long axis; TSA = tip short axis.

The coefficient for the TLA dimension was negative in sign which implies that the larger the TLA dimension of the canal segment of an earmold, the less likely it is that the earmold will provide a static pressure seal. Apparently earmolds with rounder tips are thore likely to provide a static pressure seal than those with more elliptical tips (Figure 9). A similar trend, which did not reach statistical significance in the case of the TLA dimension, is observable in the results of Experiment 1. A possible explanation is that the walls of the cartilaginous segment of the ear canal are flexible and tend to become rounder under the pressure of impression material. The better the impression material fills the ear canal in the region of the tip, the rounder the tip of the impression, and the rounder the tip of the earmold made from the impression.

\section{EXPERIMENT 4: MULTISTAGE IMPRESSIONS}

This experiment examined the comparative effectiveness of another type of impression modification which can be carried out by the impression taker, the three-stage impression technique developed by Fifield et al (3). The multistage technique was developed because of shortcomings of impression buildup by earmoldmakers. It was pointed out that although earmoldmakers develop considerable skill in applying sufficient wax to the impression to make a tight seal (but not so much that the earmold is uncomfortable to wear for long periods), the process is carried out without checking the buildup in the client's ear to make sure that the seal is effective or that the ear will accept the buildup without discomfort. Since each ear is different, errors sometimes occur in applying either too much or too little buildup, or applying it in the wrong place (3).

Multistage impressions are formed in three stages. In the first, a primary impression of the ear is obtained with a heavy-bodied impression material. Sixty $\mathrm{mm}$ of tubing is embedded in this impression and used in the second stage to test whether or not the impression provides a static pressure seal of the ear. In the second stage, a medium-bodied impression material is applied in a thin coating to the surface of the primary impression from the tip of the ear canal segment to just outside the entrance to the canal; the impression is then reinserted into the ear. Gentle pressure is applied for a short time to the outside of the primary impression in the region of the entrance to the canal assisting the material to flow.

When the coating has set, the impression is removed from the ear, inspected, and returned to the ear. The air pump of an impedance meter is connected to the embedded tubing and the static air pressure in the ear canal is increased slowly to a maximum of $200 \mathrm{daPa}$ and maintained at that level for 5 seconds. If there is no loss of pressure in that time, the impression is considered to be sealing the ear satisfactorily. This test is carried out while clients open and close their jaws to ensure that leakage does not occur during these movements. If there is a drop in pressure during the test, the impression requires further buildup and 


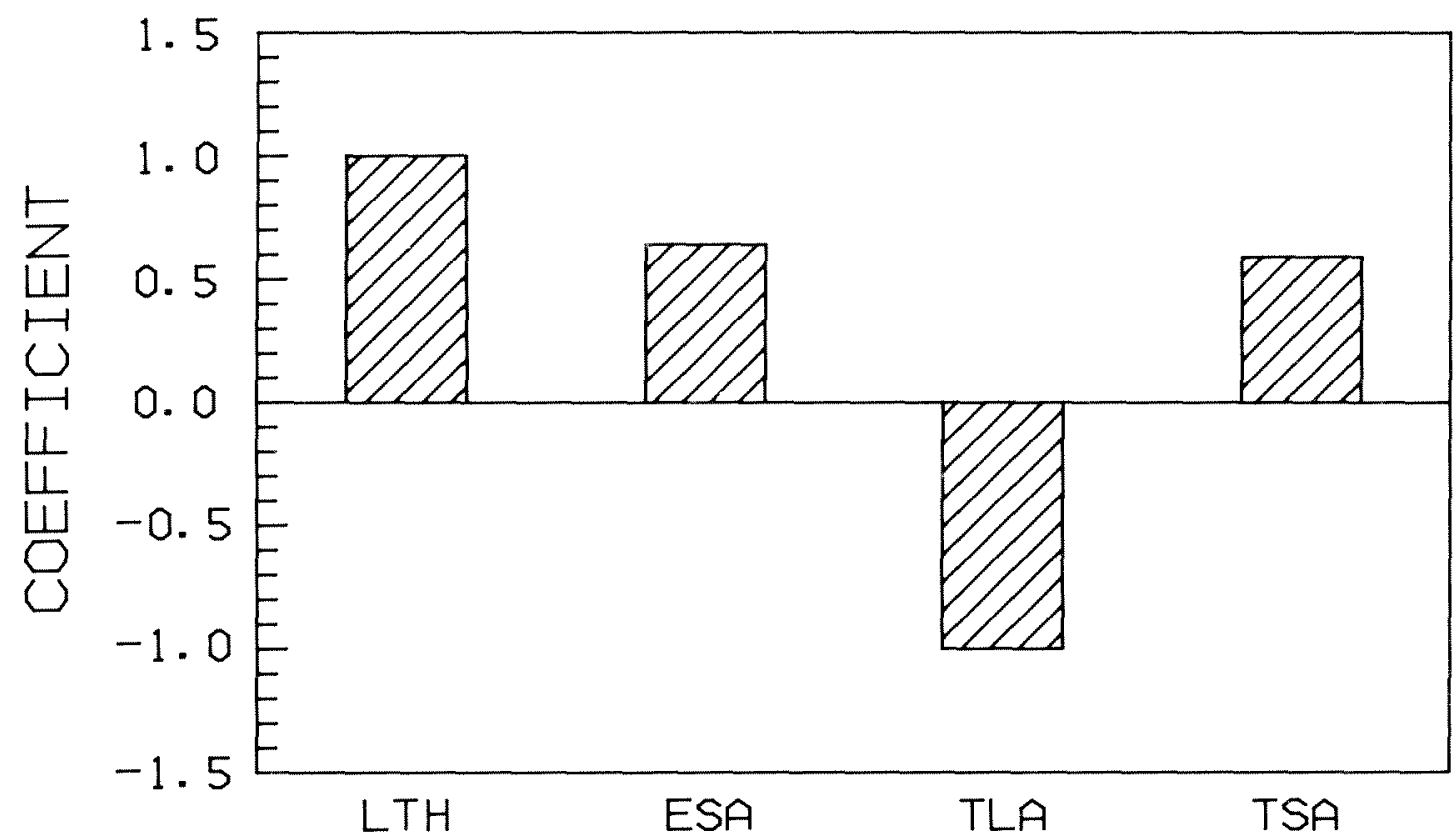

Figure 8.

Standardized canonical discriminant function coefficients for the dimensions which entered the discriminant function as significant predictors of static pressure seal.

\section{CROSS-SECTIONAL AREA OF TIP OF EARMOLD}

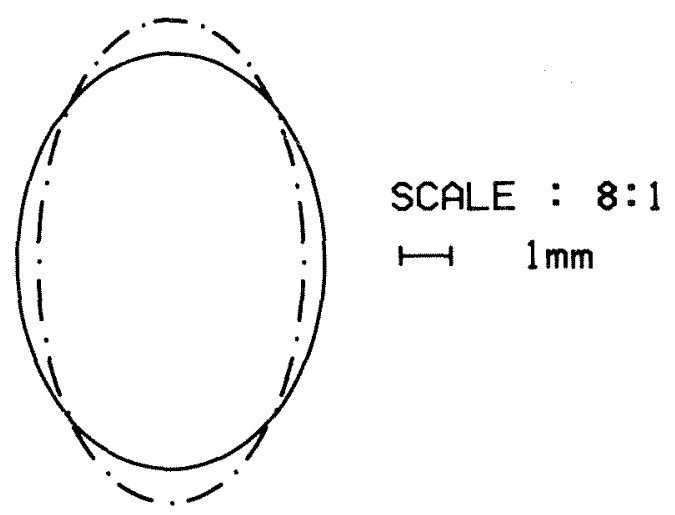

\section{STATIC PRESSURE SEAL}

\section{- - STATIC PRESSURE LEAK}

\section{Figure 9.}

Schematic diagram of the tip of the ear canal segment of two earmolds from the same individual. The earmold with the rounder tip is more likely to provide a static pressure seal than the earmold with the more elliptical tip. the second stage is repeated until a satisfactory seal is achieved.

The third stage records the fine detail of the structure of the ear on the impression and provides a smooth finish to the buildup. If required, the length of the canal segment of the impression can be increased during this stage without further buildup. A thin-bodied impression material is syringed into the ear canal and over the surface of the concha and the impression is reinserted into the ear. When this material has set, the impression is removed from the ear and inspected. Where the impression has been built up and is sealing against the canal wall, the material used previously for the buildup shows through the final coating. The earmold laboratory is instructed that the impression must not be built up or modified before the earmold is manufactured. When the earmold is returned from the earmold laboratory, it is tested to establish whether it provides a static pressure seal of the ear.

\section{Method}

Subjects. Sixteen of the 20 subjects who participated in Experiment 3 were available for this experiment. Ten subjects were male and six were female. Their ages ranged 
Journal of Rehabilitation Research and Development Vol. 27 No. 4 Fall 1990

Table 7.

Results of analyses of variance carried out on the dimensions of the various types of earmold.

\begin{tabular}{ccrrrrr}
\hline \multirow{2}{*}{ DIMENSION } & SOURCE & $\begin{array}{c}\text { Sum of } \\
\text { Squares }\end{array}$ & $\begin{array}{c}\text { Mean } \\
\text { df }\end{array}$ & Square & F-ratio & p \\
\hline \multirow{2}{*}{ LTH } & Effect & 6.9 & 5 & 1.4 & 1.4 & .224 \\
& Error & 72.9 & 75 & 1.0 & & \\
ELA & Effect & 14.3 & 5 & 2.9 & 12.8 & .000 \\
& Error & 16.8 & 75 & 0.2 & & \\
ESA & Effect & 27.5 & 5 & 5.5 & 28.6 & .000 \\
& Error & 14.4 & 75 & 0.2 & & \\
TLA & Effect & 8.8 & 5 & 1.8 & 6.4 & .000 \\
& Error & 20.7 & 75 & 0.3 & & \\
TSA & Effect & 3.8 & 5 & 0.8 & 4.4 & .002 \\
& Error & 12.7 & 75 & 0.2 & & \\
\hline
\end{tabular}

LTH = length of canal segment ELA $=$ entrance long axis; $E S A=$ entrance short axis; TLA $=$ tip long axis; $T S A=$ tip short axis; $d f=$ degrees of freedom; $\mathrm{p}=$ probability.

Table 8.

Planned comparisons of the differences between dimensions of the various types of earmold.

\begin{tabular}{|c|c|c|c|c|c|c|c|c|}
\hline \multirow[b]{3}{*}{ COMP. } & \multicolumn{8}{|c|}{ DIMENSION } \\
\hline & \multicolumn{2}{|c|}{ ELA } & \multicolumn{2}{|c|}{ ESA } & \multicolumn{2}{|c|}{ TLA } & \multicolumn{2}{|c|}{ TSA } \\
\hline & $\mathbf{F}$ & $\mathbf{p}$ & $\mathbf{F}$ & $\mathbf{p}$ & $\mathbf{F}$ & $\mathbf{p}$ & $\mathbf{F}$ & $\mathbf{p}$ \\
\hline U-P & 2.1 & .169 & 0.6 & .468 & 1.7 & .206 & 2.9 & .106 \\
\hline U-A & 28.9 & .000 & 26.9 & .000 & 35.9 & .000 & 12.8 & .003 \\
\hline U-B & 63.4 & .000 & 51.0 & .000 & 10.7 & .005 & 13.3 & .003 \\
\hline $\mathrm{U}-\mathrm{C}$ & 79.8 & .000 & 67.7 & .000 & 43.3 & .000 & 17.5 & .001 \\
\hline$U-M$ & 6.4 & .022 & 76.4 & .000 & 8.0 & .012 & 5.1 & .037 \\
\hline $\mathrm{P}-\mathrm{A}$ & 28.0 & .000 & 38.9 & .000 & 14.3 & .002 & 7.0 & .018 \\
\hline P-B & 90.9 & .000 & 70.9 & .000 & 5.5 & .032 & 4.9 & .040 \\
\hline $\mathrm{P}-\mathrm{C}$ & 81.4 & .000 & 76.8 & .000 & 7.8 & .013 & 9.1 & .009 \\
\hline P-M & 9.1 & .009 & 54.2 & .000 & 2.9 & .107 & 0.4 & .556 \\
\hline$A-B$ & 4.5 & .048 & 1.8 & .193 & 2.3 & .145 & 0.7 & .432 \\
\hline $\mathrm{A}-\mathrm{C}$ & 18.1 & .001 & 10.2 & .006 & 0.0 & .904 & 0.0 & .880 \\
\hline$A-M$ & 0.5 & .496 & 10.8 & .005 & 0.9 & .362 & 0.6 & .443 \\
\hline $\mathrm{B}-\mathrm{C}$ & 6.2 & .024 & 3.2 & .092 & 2.0 & .179 & 1.6 & .217 \\
\hline $\mathrm{B}-\mathrm{M}$ & 0.0 & .853 & 9.4 & .008 & 0.0 & .859 & 0.3 & .598 \\
\hline $\mathrm{C}-\mathrm{M}$ & 1.9 & .189 & 4.6 & .047 & 0.7 & .429 & 0.9 & .364 \\
\hline
\end{tabular}

$\mathrm{U}=$ unpatted; $\mathrm{P}=$ patted $\mathrm{A}=$ buildup $\mathrm{A} ; \mathrm{B}=$ buildup $\mathrm{B} ; \mathrm{C}=$ buildup $\mathrm{C}$; $\mathrm{M}=$ multistage; $\mathrm{F}=\mathrm{F}$-ratio; $\mathrm{p}=$ probability. from 22 to 48 years, with a mean of 37 years. The same ear was used in this experiment as in Experiment 3.

Procedure. A multistage impression of the test ear of each subject was made with ${ }^{\circledR}$ Reprosil impression materials by D.B. Fifield, one of the originators of the technique. All of the impressions provided a static pressure seal of the ear at an overpressure of $200 \mathrm{daPa}$ in the ear canal. Silicone rubber earmolds were made from the impressions, with instructions to the earmoldmaker not to use any form of buildup on the impression. When returned from the earmoldmaker, the earmolds were tested to establish whether they maintained a static pressure seal of the ear.

\section{Results}

Static pressure seal. Fourteen earmolds provided a static pressure seal at an overpressure of $200 \mathrm{daPa}$ in the ear canal but there was slow leakage around one earmold and very slow leakage around another. An $X^{2}$ test was used to assess the significance of the difference between the proportion of multistage (MS) earmolds which provided a static pressure seal (14/16 or 87.5 percent), and the proportion of specially built-up earmolds of Experiment 3 which provided a seal (33/60 or 55 percent). (The results for the three categories of specially built-up earmolds were pooled because they were not significantly different.) The difference was significant $\left(X^{2}=5.65, p=0.017\right)$.

Dimensions. Figure 10 compares the mean dimensions of the MS earmolds in Experiment 4 with the earmolds made for the same subjects in Experiment 3. The significance of the differences between the mean dimensions of the various types of earmolds was evaluated by repeated measures of analysis of variance, the results of which are given in Table 7. The differences were significant for the ELA, ESA, TLA, and TSA dimensions, but not for the LTH dimension. The results of planned comparisons for the ELA, ESA, TLA, and TSA dimensions are given in Table 8. The relationships between the mean dimensions of the MS earmolds and those of the specially built-up earmolds are of particular interest. The differences in the ELA, TLA, and TSA dimensions of the MS and specially built-up earmolds are not statistically significant. The MS earmolds are significantly larger in the ESA dimension than the specially built-up earmolds.

\section{Discussion}

Earmolds made from multistage impressions can be expected to provide a static pressure seal more frequently than earmolds made from impressions which have been specially built up by earmoldmakers. This occurred undoubtedly because the multistage impressions are built 

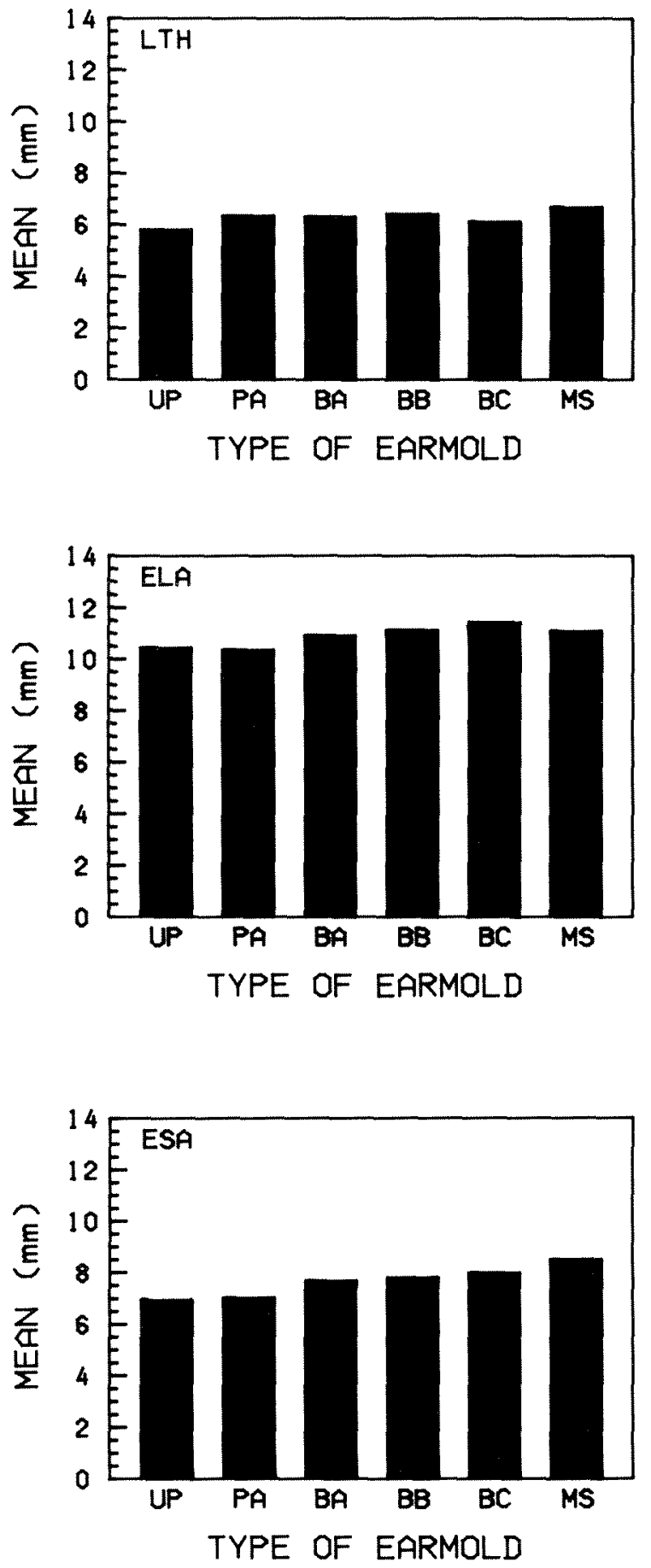

Figure 10.

Mean dimensions of the multistage earmolds made for the subjects in Experiment 4 compared with those of the various types of earmold made for the same subjects in Experiment 3.
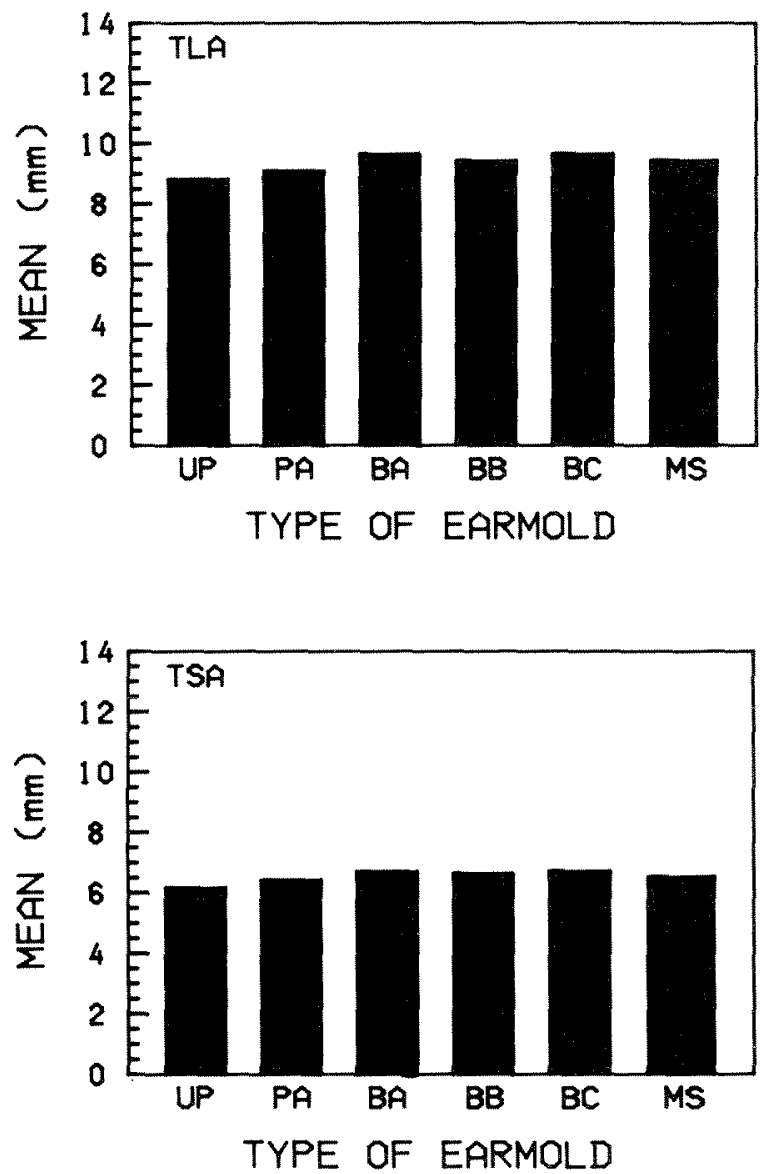

up in the ear to the point where they provide a static pressure seal. Earmolds made from multistage impressions are built up in a manner that conforms to the structures of the individual ear and therefore provide a standard against which buildup applied by earmoldmakers can be compared. The earmoldmaker apparently did not apply sufficient buildup to the ESA dimension and the proportion of specially builtup earmolds that provide a seal could possibly be augmented by increasing the amount of special buildup applied to this dimension.

Despite the fact that earmolds made from multistage impressions provide a static pressure seal more frequently than earmolds made from impressions specially built up by the earmoldmaker, earmoldmaker buildup is generally preferable because it is a considerably less expensive technique. The earmoldmaker does not charge extra for building up impressions. It takes about 1 hour to obtain a multistage impression as opposed to approximately 20 minutes for an ${ }^{\circledR}$ Otikon Putty impression, and the materials used in making multistage impressions are considerably more expensive than ${ }^{\circledR}$ Otikon Putty. 
The multistage technique should therefore be confined to clients for whom an adequate acoustic seal cannot be obtained with earmoldmaker buildup. In the study of the hearing aid gain requirements of adults with severe to profound hearing impairment carried out recently at NAL by Byrne, Parkinson and Newall,* only 3 out of 47 subjects (6 percent) required earmolds made from multistage impressions in order to obtain a satisfactory degree of acoustic seal. The remaining 44 subjects ( 94 percent) obtained adequate acoustic seal with earmolds made from impressions which had beer built up by the earmoldmaker. Because only about 10 percent of the clients of NAL require high-gain hearing aids (4), only about six out of every 1,000 hearing aid users will require earmolds made from multistage impressions.

\section{CONCLUSIONS}

The needs of clients who require the minimum amount of sound radiating out of the ear during hearing aid use are best met by earmolds which seal the ear. The chance of sealing the ear with earmolds made by the ordinary twostage technique with only general buildup of the impression is about 10 percent, and it is unlikely that the use of any of the current impression or earmold materials significantly improves the chance of obtaining a seal. The chance of obtaining a seal with multiple two-stage earmolds made from the one impression is zero, or very close to zero when made by the technique used for this project.

*Denis Byrne, Aaron Parkinson, and Philip Newall: In-person conversation, July 9,1989
The chance of sealing the ear increases to approximately 55 percent when the earmold is made from an impression which is specially built up by the earmoldmaker. Earmolds made from multistage impressions can be expected to provide a static pressure seal more frequently than earmolds made from impressions which have been specially built up by the earmoldmaker (approximately 87.5 percent as compared with 55 percent). In order to maximize the chances of sealing the ear with an earmold, the earmold should be made from a multistage impression. However, earmoldmaker buildup is preferable to multistage buildup for the average client because it is considerably less expensive. The multistage technique should therefore be confined to clients for whom adequate acoustic seal cannot be obtained with earmoldmaker buildup. Only about six percent of clients with severe to profound hearing impairment, or six out of every 1,000 hearing aid users, will require earmolds made from multistage impressions.

\section{REFERENCES}

1. Boothroyd A: The provision of better earmolds for deaf children. J Laryngol Otol 79:320-335, 1965.

2. Cox RM: Acoustic aspects of hearing aid-ear canal coupling systems. Monographs in Contemporary Audiology. Vol. 1. No. 3. Minneapolis: Maico Hearing Instruments, 1979.

3. Fifield DB, Earnshaw R, Smither MF: A new impression technique to prevent acoustic feedback with high powered hearing aids. Volta Rev 82:33-39, 1980.

4. Macrae JH, Dillon H: Updated performance requirements for hearing aids. J Rehabil Res Dev 23(3):41-56, 1986.

5. Nolan M: Acoustic feedback-causes and cures. $J \mathrm{Br}$ Assoc Teach Deaf 7:13-17, 1983. 